\title{
Alteridade, Expatriação e Trabalho: Implicações para a Gestão Organizacional
}

\author{
Hilka Vier Machado \\ Cláudio Aurélio Hernandes
}

\section{Resumo}

A alteridade consiste na relação do indivíduo com o outro. É por meio dessa troca que cada um constrói ou reconstrói sua identidade. Por outro lado, situações de expatriação requerem redefinição das identidades, tanto no plano individual quanto no social. Tendo em vista esses aspectos, este estudo qualitativo e exploratório foi realizado sob a forma de estudos de casos, junto a nove pessoas que saíram de seus países de origem para trabalhar em outro país. O objetivo do estudo é investigar o processo de alteridade em expatriados e as suas implicações nas situações de trabalho. Os dados foram coletados por meio de entrevistas semi-estruturadas, gravadas e transcritas. O conteúdo foi analisado com apoio do software Nvivus e as seguintes categorias foram extraídas dos discursos: vida de expatriado, vida de repatriado e situações de trabalho. Finalmente, com base nos resultados encontrados, discute-se implicações do estudo nas organizações e na gestão organizacional.

Palavras-chave: identidade; alteridade; expatriação; relações de trabalho.

\begin{abstract}
Alterity consists of a relation between an individual and other. It is by means of this exchange that each one builds or rebuilds their identity. On the other hand, expatriation situations demand a redefinition of identities both in the individual and social plans. Considering these aspects, this qualitative and exploratory study was carried out in the form of case studies with nine people who have left their countries to work in another. The objective of the study is to investigate the alterity process in expatriates and its implications in work situations. The data were collected by means of semi-structured interviews, which were recorded and then transcribed. Their content was analyzed using Nvivus software and the following categories were extracted from their speech: expatriate's life, repatriate's life and work conditions. Finally, based on the results, it is discussed the implications of this study on organizations and organizational management.
\end{abstract}

Key words: identity; alterity; expatriation; work relations. 


\section{INTRODUÇÃO}

Uma das características da sociedade contemporânea é a facilidade com que indivíduos se deslocam de um país para trabalhar em outra localidade. Essa mobilidade tem sido cada vez mais intensa, independentemente da atividade ou posição hierárquica a ser ocupada. Esse movimento resulta na predominância de um mundo cultural diverso e múltiplo dentro das organizações.

A decisão de trabalhar em outro país pode ocorrer de maneira voluntária, quando o indivíduo decide exercer sua atividade profissional em outra nação; ou de forma involuntária, quando a organização designa o empregado para um posto de trabalho em outra filial no exterior.

Em qualquer dessas situações, o que acontece é que a pessoa se depara com duplo desafio: o de enfrentar a nova atividade ou organização e o de conviver em outra cultura. Como cada cultura fornece ao indivíduo um esquema inconsciente para todas as atividades da vida (Cuche, 1996, p. 36), para viver em outro meio social torna-se necessário, pelo menos o conhecimento, a percepção e a aceitação de novos valores culturais. Essa atitude, no entanto, só é possível a partir da relação com o outro, em processos de interação e de aceitação mútua, que são importantes para a construção da nova identidade social, que se produz pela integração em outra cultura.

Nesse sentido, o fenômeno da alteridade pode ser entendido como a relação entre o eu e o outro, pois "em cada eu há um outro - que não sou eu, que é diferente de mim, mas que eu posso compreender e assimilar" (Baudrillard E Guillaume, 1994, p.10). Desta forma, o eu pode ser o estrangeiro, o imigrante ou indivíduos que se expatriam para trabalhar.

Embora alguns estudos (Joly in Chanlat, 1992; Kets de Vries, 1997; Freitas, 2000) tenham procurado discutir as implicações presentes nestes casos, estes têm-se limitado, em geral, em considerar casos de executivos expatriados. Deste modo, outras modalidades de trabalho por expatriados, em diferentes atividades e níveis hierárquicos, são pouco exploradas.

O objetivo deste estudo é o de investigar o processo de alteridade em expatriados e as implicações nas situações de trabalho. Para consecução deste fim, realizouse um estudo qualitativo com nove casos de pessoas que foram trabalhar fora do 
seu país de origem, em atividades e posições de naturezas diversas. Assim, os casos estudados referem-se a indivíduos em diferentes situações de trabalho: como empreendedor fora do país de origem, assumindo cargo gerencial, exercendo atividades no nível operacional e um caso de trabalho autônomo.

A apresentação do estudo inicia-se por uma discussão sobre alteridade e expatriação e, em seguida, apresentam-se os casos, com suas respectivas análises. Após a apresentação das categorias, derivadas da análise dos dados, discute-se as implicações do estudo.

\section{Alteridade e Expatriação}

A alteridade é fenômeno de caráter relacional, uma construção psicológica em torno da relação entre o eu e o outro. Qualquer relação "é uma realidade que para existir depende da outra” (Guareschi, 2002, p.151). Assim, o caráter relacional é o campo de cultivo da alteridade. A existência do eu, a partir da relação com o outro (Ricoeur, 1990) permite ao indivíduo ter a consciência de si, pois, "somente através da mediação de outros o 'eu’ pode refletir sobre si mesmo” (Jovchelovitch, 2002, p. 74).

O reconhecimento do outro favorece a compreensão de si. É por isso que, em situações de confronto com outras culturas, diferentes da de sua origem, o indivíduo vive um conflito psicológico, decorrente da dificuldade em reconhecer o outro. Deste modo, como o outro é um estranho, a "afeição de si é o suporte da troca regulada entre o eu e o outro” (Ricoeur, 1990, p. 384). Nos processos de interação, o alvo é a tentativa de fazer com que o outro não esteja condenado a permanecer estranho, mas que possa tornar-se meu semelhante (Ricoeur, 1990, p. 384).

Como a relação com o outro é um dos elementos que constrói a visão de si mesmo, identidade e alteridade são indissociáveis (Cuche, 1996) e são ligadas por relação dialética, pois não somente a identificação com o outro interfere na construção da identidade, mas também a diferenciação do outro. Deste modo, o processo de inserção social do indivíduo acontece pelas identificações e pelas diferenciações, por meio das quais se estabelece a fronteira psicológica entre os limites do eu e do outro. Outro aspecto importante, além do impacto individual, é a necessidade de interação social dos indivíduos, ou a necessidade de autocategorização, que consiste na vinculação da pessoa a diferentes grupos e fornece sentido à sua própria existência, pois “a identidade de um grupo repousa 
sobre uma representação social construída, sobre a qual uma coletividade toma consciência de sua unidade pela diferenciação dos outros” (Dubar, 1996). Esses acontecimentos se processam em contexto cultural determinado; portanto identidade, alteridade e cultura estão interligadas.

A compreensão da cultura é bastante complexa, tanto em termos sociais, quanto organizacionais. Embora não se trate do objetivo principal deste estudo, algumas implicações culturais são importantes para compreender o fenômeno da alteridade. Uma delas diz respeito à classificação das culturas em individualistas e coletivistas (Hofstede, 1997; Deschamps et al., 1999). O primeiro tipo enfatiza o indivíduo como unidade fundamental de sobrevivência, enquanto o segundo enfoca o grupo. Isso implica a regulação da conduta social, centrada em atitudes pessoais no primeiro caso, e nas regras do grupo para o segundo caso. Nas sociedades individualistas, a diferença entre o grupo a que se pertence e o de não pertencimento é mais fraca; em contrapartida essa diferença é mais forte para as culturas coletivistas. Nas culturas individualistas predominam relações horizontais contra as verticais e o predomínio de grupos de vinculação mais homogêneos para as culturas coletivistas. Outro aspecto importante é que nas sociedades individualistas o sucesso é tido como resultado do esforço do indivíduo e há maior separação dos papéis nos grupos (Deschamps, 1999, p. 177). Para Markus e Kitayama (apud Deschamps, 1999) as culturas individualistas podem ser compreendidas como culturas do eu independente e as coletivistas como as culturas do eu interdependente.

Em situações de expatriação a alteridade é eminente. Expatriar significa ir residir em país estrangeiro e, para Freitas (2000, p. 3), essa experiência consiste em "reassociar emoções com fatos e gestos familiares e ao mesmo tempo estranhos, aprender a ler as linhas e entrelinhas, revelando simultaneamente a estranheza e a familiaridade, provocando confusão de referências, sentidos e emoções já estabelecidos”. Isso ocorre porque, no início da expatriação, o estrangeiro sente-se à margem do grupo, porque ainda não partilha das mesmas leis, do mesmo passado, da mesma língua; enfim, não lhe são comuns todos os aspectos que fazem parte da identidade do grupo. A sua aproximação será gradativa, à medida que ele conseguir reduzir as diferenças entre o eu e o outro. Para isso, é preciso que certo tempo de vivência na cultura tenha ocorrido.

Kets de Vries (1997) aponta alguns problemas relacionados à experiência de executivos expatriados. O primeiro deles é a ausência de programas preparatórios, por parte das empresas, que alertem para as situações de conflito e dificuldade que os indivíduos terão de enfrentar, vivendo em outro país. Para o autor, o choque 
cultural acontece em função de uma série de diferentes indicadores auditivos, visuais ou olfativos que provocam uma confusão inicial. Fatores familiares também precisam ser gerenciados nessas situações. Se, por um lado, viver uma experiência de expatriado em família reforça os laços familiares, conforme essa situação cria uma cumplicidade mútua, o compartilhamento de momentos de crises extremas cria entre os indivíduos laços que são tão fortes quanto às próprias crises compartilhadas. Apesar disso, a família pode representar um problema em determinadas situações; por exemplo, quando um dos cônjuges deixa sua atividade profissional para acompanhar o outro. Nesses casos, a experiência tem demonstrado que é importante a inserção desses acompanhantes em outra atividade que lhes possibilite um processo de socialização no novo país.

Joly (in Chanlat, 1996) apresenta quatro fases da experiência existencial no estrangeiro. A primeira delas é o encantamento, marcada por descobertas e desafios. Em seguida, ocorre o negativismo extremo: esta fase caracteriza-se pelo domínio da linguagem, que contribui para a compreensão do mundo simbólico da cultura vivenciada. A terceira fase, de que o autor faz menção, trata-se de guardar distância ou integrar-se, constituindo a decisão entre rejeitar definitivamente a nova cultura ou tornar-se nativo. Finalmente, a última fase é o choque da volta, porque o indivíduo que retorna não é mais o mesmo que deixou sua pátria.

Para Ricouer (1990, p. 395), a última fase do processo de interação do eu com o outro constitui a substituição, "em que culmina a força da hipérbole e se exprime no seu mais extremo vigor a filosofia da alteridade”. Para Kets de Vries (1997), a volta ao lar corresponde à situação de repatriados e estes "costumam ter um choque cultural em sua volta”. Em uma experiência de expatriação, a visão de nova realidade cultural colabora para que o indivíduo veja sob outro ângulo sua própria cultura. Sendo assim, os expatriados percebem com o tempo que seus conceitos se alteram e que suas referências não são as mesmas. Isso ocorre depois que o indivíduo compreende a nova realidade e passa a vivenciá-la.

O choque cultural, ou as batalhas culturais a que se refere Ribeiro (1995) e a renovação da identidade de indivíduos expatriados acarretam conseqüências para as práticas de gestão, tais como a dificuldade de reter executivos com experiência internacional no quadro da organização, necessidade de avaliações e planos de carreiras próprios para essas situações (Joly in Chanlat, 1992).

Embora o processo de expatriação ocasione impacto no desenvolvimento profissional e na reintegração desses indivíduos ao trabalho, os estudos realizados sobre esse tema têm-se limitado a descrever situações desta natureza, considerando 
apenas os casos de executivos. Entretanto há outros tipos de atividades desenvolvidas por expatriados, que não têm sido exploradas na literatura. É possível que aspectos relativos à alteridade estejam presentes em situações enfrentadas por indivíduos que realizam outra atividade, que não somente como executivos, sendo que essas situações também estão relacionadas à dinâmica organizacional e do trabalho. Nesse sentido, o presente estudo procurou explorar experiências de alteridade, expatriação e situações de trabalho nas seguintes modalidades: trabalho executivo, atividade como empresário, trabalho de empregado em níveis operacionais e trabalho autônomo.

\section{Metodologia}

Este estudo é de caráter exploratório e de natureza qualitativa, com foco descritivo e interpretativo sobre casos de alteridade e expatriação. O método utilizado foi o de estudos de casos, tendo em vista o pouco conhecimento em torno do objeto de estudo, o que resulta em maior necessidade de caráter intensivo do que extensivo na investigação. Além disso, como salienta Yin (1988), estudos de casos são recomendados para estudar eventos contemporâneos, que requerem contato direto com os sujeitos do estudo e são utilizados quando as questões de pesquisa estão estruturadas de forma a averiguar-se por que ou como determinados eventos acontecem.

Os sujeitos deste estudo são formados por indivíduos que passaram por experiência de expatriação e trabalho. Consideram-se como expatriados os indivíduos que deixaram seu país de origem e foram exercer alguma atividade profissional em outro país. Como situações de trabalho, a maior diversidade possível foi considerada, conforme descrição a seguir.

A amostra foi constituída por nove casos, selecionados pelo critério de diversidade de atividades de trabalho e de países. As atividades realizadas como expatriados foram: empresário, executivo, empregado de níveis operacionais e trabalhador autônomo. Quanto aos países de expatriação, fazem parte do estudo: Brasil (há 3 casos de estrangeiros que trabalham no Brasil: um chinês, dois franceses); Paraguai, Alemanha, Itália, Japão, Portugal e França. A diversidade da amostra foi projetada para atender ao objetivo do estudo, que é o de estudar o fenômeno da alteridade em diferentes situações de trabalho.

A coleta de dados foi realizada por meio de entrevistas semi-estruturadas, em 
torno dos seguintes aspectos: cultura de origem e de destino; motivos/objetivos da expatriação; situação profissional anterior à expatriação; tempo de permanência no país estrangeiro; percepção do outro; diferenças interculturais nas relações interpessoais e nas relações de trabalho. O caráter confidencial dos dados foi assegurado e as entrevistas foram gravadas, totalizando 7h22 de gravação, correspondendo a 120 páginas de material transcrito.

A análise dos dados foi realizada com a utilização do software Nvivus, com que foi feita a categorização do material. A análise preliminar do conteúdo foi realizada agrupando incidentes similares, definidos a partir de questões do tipo: Por que foi trabalhar no exterior? Que situação encontrou lá? Que situação encontrou quando retornou? Qual a sua visão do outro? Qual a visão do outro sobre você? Como era o seu trabalho lá?

Além das categorias principais, que são: vida de expatriado, vida de repatriado e situações de trabalho, algumas subcategorias foram utilizadas, como a categoria vida de expatriado, que contém estas subcategorias: a visão do outro sobre si e a visão de si sobre o outro.

\section{Apresentação dos Casos}

Dentre os nove casos que fizeram parte deste estudo, o tempo de permanência no exterior variou de 2 a 10 anos. Sete casos são de homens e dois de mulheres, sendo sete casados e dois solteiros. A idade dos entrevistados variou de 18 a 53 anos. Melhor detalhamento dos casos pode ser visualizado na Tabela 1.

Tabela 1: Características da Amostra

\begin{tabular}{|c|c|c|c|c|c|c|}
\hline Casos & Idade & Sexo & Origem & Destino & $\begin{array}{c}\text { Permanência } \\
\text { (anos) }\end{array}$ & Atividade principal \\
\hline BR/FR-01 & 47 & F & Brasil & França & 10 & Trabalho autônomo \\
\hline BR/PY-01 & 51 & F & Brasil & Paraguai & 4 & Empresaria \\
\hline BR/PT-01 & 18 & M & Brasil & Portugal & 2 & Operário \\
\hline BR/AL-01 & 55 & M & Brasil & Alemanha & 4 & Gerente adjunto \\
\hline BR/JP-01 & 28 & M & Brasil & Japão & 3 & Operário \\
\hline BR/IT-01 & 39 & M & Brasil & Itália & 3 & Empresário \\
\hline FR/BR-01 & 28 & M & França & Brasil & 2 & Gerente \\
\hline FR/BR-02 & 53 & M & França & Brasil & 4 & Diretor geral \\
\hline CH/BR-01 & 50 & M & China & Brasil & 18 & Profissional liberal \\
\hline
\end{tabular}


O caso BR/FR-01 expatriou-se quando tinha 33 anos e retornou há 3 anos. Antes de mudar-se para a França trabalhava como bancária e como professora de francês. Durante todo o tempo de permanência no outro país trabalhou como autônoma em serviços gerais. O segundo caso é uma mulher, que se expatriou com 46 anos para o Paraguai, para abrir uma empresa (restaurante). Anteriormente, ela tinha tido experiência no Brasil com empresa varejista no ramo alimentício (conservas e condimentos). O caso BR/PT-01 é um jovem solteiro que foi trabalhar em Portugal como garçom. O quarto caso expatriouse por exigência de seu trabalho. Antes de ir para Alemanha era executivo de um banco brasileiro. Foi escolhido para o cargo por possuir os conhecimentos das rotinas bancárias e por ter fluência no idioma. Foi expatriado para ser o gerente-adjunto de uma agência bancária na Alemanha. Após seu retorno, aposentou-se. BR/JP-01 foi para o Japão trabalhar como operário em duas empresas. Antes da expatriação trabalhava como técnico no ramo de segurança eletrônica. O caso BR/IT, antes de mudar-se para a Itália, atuava como executivo no comércio internacional no ramo da seda. Trabalhou como gerente deste setor em uma cooperativa de grande porte e abriu pequena empresa na Itália, no mesmo ramo. FR/BR-01 é um francês que veio para o Brasil desenvolver um projeto de empresa francesa, exercendo a função de gerente de desenvolvimento. O caso FR/BR-02 é de outro francês, atualmente diretor geral de uma filial brasileira de indústria francesa. O último caso, $\mathrm{CH} / \mathrm{BR}$, tratase de um chinês que trabalha como autônomo no Brasil.

Pela breve descrição dos casos, verifica-se que diferentes situações de trabalho estão contempladas pelos sujeitos do estudo, bem como uma diversidade quanto à idade, ao tempo de permanência, a nacionalidades e ao sexo. Apesar dessa diversidade, a análise das entrevistas resultou em três grupos de categorias principais: a vida de expatriado, vida de repatriado e situações de trabalho.

\section{Vida de Expatriado}

Observou-se nos casos analisados que algumas variáveis podem determinar diferentes situações e reações na fase inicial da expatriação. Um dos aspectos foi a existência de outra experiência anterior fora do país. Nos casos de brasileiros e de estrangeiros que tinham passado por outra experiência de expatriação, ainda que não estivesse vinculada a alguma situação de trabalho, o impacto inicial foi menor que nos outros casos. Outra variável que interferiu foi o domínio do idioma, que contribuiu para uma inserção mais rápida na nova cultura. Um terceiro aspecto que teve impacto na situação dos expatriados foi o acompanhamento da família. 
Aqueles casos que permaneceram no exterior sem a família ressaltaram esse aspecto como uma das maiores dificuldades para a vida de expatriado.

O início da vivência em uma nova cultura pode desencadear dois tipos diferentes de reações, dependendo das experiências de cada um; são elas: choque ou encantamento. Os seguintes depoimentos dão a idéia do encantamento e do processo cognitivo que acompanham essa fase:

“.. eu gostei, tudo para mim lá era novidade e outra, eu já gostava, porque eu ia conhecer pessoas...eu gostei, tudo o que eu fui aprendendo, porque eu aprendo rápido; também porque você chega e vê tudo diferente e você esquece o que tem aqui e começa a aprender tudo o que tem lá, e é tudo diferente; e também muito rápido então você tem que começar a aprender muita coisa, muito rápido”.

"Você aprende que o seu jeito não é o melhor jeito de fazer, o jeito certo".

"Quando você mora fora você aprende que existe outro jeito de viver”.

"Apesar do contraste entre o velho e o novo, mas é sempre novidade, você pode já ter passado ali e viu uma coisa do outro lado e pode não ter visto aquilo; então sempre que você olha, acaba vendo coisas bonitas”.

Por outro lado, este outro depoimento de um expatriado que veio ao Brasil, juntamente com a família, aproxima-se mais de uma situação de choque cultural:

"Quando ela chegou, fomos assaltados; nem quinze dias depois que ela tinha chegado, fomos assaltados. Roubaram toda a casa. Aí, minha esposa queria ir embora”.

Mesmo que a reação inicial seja mais voltada para o choque do que para o encantamento, o indivíduo descobre outro mundo diferente do que vivia:

"Em francês há uma palavra que é insouciance, que significa quando você não faz pergunta do que será o amanhã para você e aí você chega aqui e tem gente que está lutando para dar de comer aos seus filhos!”

Assim, a fase inicial dos expatriados foi marcada pela percepção de si como diferente do outro. Por essa razão um esforço de adaptação à nova cultura é desencadeado, a fim de reduzir essa distância, como mostra o seguinte depoimento: 
“ Você tem a oportunidade de, morando fora, se você quiser deixar sua régua de lado, começar a tentar entender o outro; você aprende coisas boas e leva uma vida mais tranqüila. Mas, se você quiser usar sua régua você não agüenta. Se você quiser ficar enquadrando todo o mundo naquele jeito que você tem de pensar e que esse é o jeito correto .... Até você perceber que não dá para medir o mundo com a sua régua, que existe outra escala...”

Nessa fase inicial, os depoimentos demonstram que a sensação desses indivíduos corresponde a descrever o "eu" na terra do "outro". A primeira reação, nessas circunstâncias, é procurar descobrir como o outro vê o indivíduo, a fim de ajudálo a descobrir as diferenças entre ele e a outra cultura, pois ele ainda não consegue identificar esses elementos, analisando a situação que vivencia. Uma subcategoria foi constatada: a visão do outro.

\section{A Visão do Outro sobre Si}

Uma visão negativa do outro foi encontrada nos casos brasileiros que foram expatriados, independentemente da atividade:

"Nós da América Latina, o pessoal da Romênia, da Bulgária, todo pessoal da Albânia... Estes são os extra-comunitários...”.

"Eles têm uma visão do Brasil pobre, do Brasil que não trata direito dos brasileiros, do Brasil desigual, do Brasil injusto, do Brasil da violência”.

Um dos depoimentos mostra uma soberania na visão do outro:

"Uma vez em um churrasco com o pessoal de lá eu disse que ia voltar para o Brasil. Um italiano disse: pois é, tem a questão do visto de permanência.., então eu disse que tinha visto e poderia ficar; estava voltando porque queria voltar, mas ele pensou: ele está voltando porque tem de voltar, não é que ele quer”.

A exceção desses casos foi o da brasileira que abriu empresa no Paraguai: "eles acham que os brasileiros sabem mais do que eles".

Entre os casos estrangeiros, a visão do brasileiro sobre eles também ressalta aspectos negativos: "quando eu cheguei aqui diziam que o francês era frio".

Pode-se supor que, na fase inicial do processo de expatriação, na visão do outro sobre si os aspectos negativos constituem a principal preocupação, que 
justifica para o indivíduo a distância que se instala entre ele e os outros. A partir dessa constatação é que ele forma uma visão do outro, que é outra subcategoria analisada a seguir.

\section{A Visão de Si sobre o Outro}

Na visão sobre o outro há dois tipos de manifestações: a primeira está relacionada com a falta de acolhida ou frieza da nova cultura. Esses casos corresponderam à maioria dos brasileiros, com exceção do caso que foi ser empresária no Paraguai. Esse aspecto foi mencionado em diversos casos, tais como os seguintes:

"Aqui, quando você vai pedir uma informação, a pessoa só falta pegar você no colo e levar aonde você quer ir, mas lá eles não querem nem saber, nem explicam”.

“..aqui você compra alguma coisa; todo o mundo vai comentar que você comprou; lá ninguém liga, lá se mistura pobre, rico; você não sabe quem é quem”.

O segundo tipo de visão do outro está relacionado à aceitação alheia, mencionada por um estrangeiro:

"O Brasil tem tanta mistura de população, talvez por isso é acolhedor e aceita e assimila o outro. Ele assimila, não é simplesmente aceitar, é assimilar também. O brasileiro assimila o outro e é bom que seja assim; é bom assimilar outros povos, outras culturas, mesmo conhecendo as diferenças”.

Apesar de ressaltar o aspecto afetivo com relação ao outro, na visão de estrangeiro o comportamento informal brasileiro caracteriza uma relação superficial:

"aqui a pessoa diz: vou fazer um churrasco; vai lá, mas nunca liga, insiste.

Você é sempre convidado...e o francês é diferente; se ele o convida é porque ele quer que você vá. Marca uma data e horário”.

Outro aspecto diz respeito à falta de pontualidade, como relata um estrangeiro:

“..é difícil para um francês no Brasil aceitar os prazos. O francês é uma pessoa que se tiver um compromisso às oito ele gosta de chegar quinze para as oito. E isso é uma diferença cultural a que você tem que se acostumar". 
Além de aspectos negativos na visão do outro, um dos casos apontou uma representação positiva: “...lá a pessoa fala menos, não fala muito. Aqui conversa, tipo mais alegria”.

O que se observou foi que os brasileiros que se expatriaram não tiveram um contato estreito com o pessoal nativo dos lugares, onde foram trabalhar, na maioria países europeus (Portugal, França, Itália, Alemanha). Esse fator contribuiu para a dificuldade em construir uma representação imaginária do outro. Apesar disso, em um dos casos, que permaneceu doze anos trabalhando na França, a entrevistada ponderou:

“...lá, eles são, sobretudo os franceses, muito nacionalistas; eles vão sempre dar preferência a um francês também...”.

Nos casos analisados verificou-se que a procura de uma relação com o outro, que caracteriza o fenômeno da alteridade, impregna todo o processo de expatriação. Para os casos que formularam uma representação do outro, a impressão é que eles avançaram na reconstrução de suas identidades, integrandose com a cultura local. É importante observar que diferenças foram mencionadas em expatriados para França e Itália, pois, segundo Hofstede (1997), esses países integram o mesmo grupo do Brasil para fins de categorização cultural. Contudo os resultados deste estudo demonstram que há diferenças no campo social e do trabalho.

A outra categoria resultante das análises dos conteúdos é a vida de repatriado, que revela também aspectos relativos à vivência na outra cultura.

\section{Vida de Repatriado}

O expatriado, ao ter vivido em outra cultura, percebe aspectos do seu próprio país que antes lhe passavam despercebidos ou desvalorizados. De fato, a identidade cultural se modifica; mas, por outro lado, ela é ratificada. O caso seguinte ilustra a tendência de confirmar a própria identidade após o contato com mais de uma cultura:

“..quando você assimila uma cultura, a tendência é você perder sua identidade cultural. Agora, quando você assimila várias, é muito pelo contrário; tem a tendência de você ratificar sua identidade cultural; isso é o que acontece; quando você sai, você vê o que nós temos de bom aqui, você quer morar aqui...”

Deste modo, o conhecimento de outra realidade cultural faz com que o indivíduo 
adquira parâmetros para analisar a sua cultura, propiciando-lhe avaliar aspectos positivos e negativos, os quais ele deseja incorporar ou rejeitar, tal como os seguintes depoimentos:

“...muitas vezes chego lá, o aeroporto está em greve, bagagens na mão... um país onde o salário mínimo é cem vezes maior, cinqüenta vezes maior que aqui no Brasil. Um país que tem um nível social fantástico e ainda... Acho que... principalmente o francês, muito... muito... tem uma condição de vida fantástica, todo o mundo, diferente de um país onde muita gente não tem plano de saúde, não tem como se curar de uma enfermidade... Um país onde tudo isso é negado... vai, vai morar um pouco lá para ver as coisas como são...”

“..aqui no Brasil está se desenvolvendo um capitalista à moda americana, onde o ser humano não importa nada. Se você tem um ano ou dois de trabalho, isso não faz diferença nenhuma; e é o contrário que se pratica na França. Você tem uma estabilidade, você tem um respeito e aqui, olha que nós tínhamos, mas agora está se revertendo...”

Entretanto, se novas identificações e diferenciações se constroem e, com elas, nova identidade, há também uma sensação de "perda da identidade original”, conforme ilustra o seguinte depoimento:

"Hoje eu acho que sou uma pessoa sem raiz; eu tenho, só que no sentido de onde eu nasci, onde eu cresci, não no sentido que minhas raízes estão me chamando para voltar lá. Isso é grande problema, porque depois de um tempo você não sabe de onde é..”

Além disso, a reintegração social ao grupo de origem torna-se novamente complexa, conforme ilustra um dos franceses expatriado no Brasil:

“..há uma defasagem entre mim, meus pais, meus irmãos, que vivem num mundinho pequeno... porque você vê as coisas totalmente diferentes. Quando você volta lá, entra de novo num circulo de "mesquinhez", ...alguma coisa quebra entre você e as pessoas..."

Essa dificuldade na reintegração que ocorre na repatriação pode ser compreendida pelo fato de que uma nova identidade é construída, incorporando elementos da nova cultura. Nesse momento, o indivíduo confronta-se com as identidades propostas, resultantes das culturas onde viveu e com a necessidade de assumir uma identidade. Para mostrar essa ambigüidade, fruto da expatriação, recorreu-se a dois discursos que, embora de expatriados para diferentes países 
(França e Brasil), ilustraram com os mesmos termos: "seis meses lá e seis meses aqui”, explicando nas entrelinhas que a nova identidade é definida pela incorporação das duas culturas:

“..Ah porque existem raízes no Brasil, eu gosto do Brasil também. O ideal seria passar seis meses lá e seis meses aqui, mas eu não posso, você tem que optar, você tem que escolher... “

“...Eu pretendo voltar, não quer dizer que vou deixar de vir ao Brasil. Uma discussão que eu tenho com minha esposa é passar seis meses na Europa e seis meses no Brasil, quando a gente parar de trabalhar. Passar um tempo aqui, um tempo lá... “

Ao reconstruir uma nova identidade, o repatriado altera a visão original que tinha sobre si, tal como ilustra o seguinte depoimento:

“..agora acho o francês mais frio. Já chegando no aeroporto, eu já me sinto diferente..”

Também através da incorporação do idioma essa reconstrução da identidade pode ser observada:

"Quando minha esposa fala: você trouxe isso aí, não sei o que... eu digo "esqueci"; mesmo se ela me fala em francês eu falo "esqueci" em português, pois eu gosto dessa palavra, parece que é menos grave.”

Finalmente, uma das dificuldades encontradas na repatriação é a necessidade de o próprio indivíduo aceitar a sua volta. Essa dificuldade é resultante do conflito interno que ele tem para se convencer de que novamente terá de se adaptar à situação anterior, sendo que ele não é mais o mesmo. Esse aspecto pode ser constatado no seguinte depoimento:

"a hora de voltar foi marcante. Eu saí daqui, sabendo que voltaria; mas, quando eu disse "eu vou voltar”, caiu a ficha, pois até então eu nunca tinha voltado. Eu morei em Franca, depois fui para Londrina, depois para Maringá; então eu sempre fui, nunca voltei.”

Pelos discursos analisados, pode-se verificar que a mesma tentativa de definir ou redefinir o outro e a si mesmo embebe a vida do expatriado e do repatriado. É provável que as diferenças de culturas, mais individualistas nos casos brasileiros e mais coletivistas nos casos europeus, tenham contribuído para visões muitas vezes antagônicas do outro. Além disso, esses conflitos e dificuldades que o 
indivíduo enfrenta no plano social e psicológico, decorrentes da expatriação, exercem impacto nas situações de trabalho que serão abordadas a seguir.

\section{Situações de Trabalho}

No que diz respeito às situações vivenciadas no trabalho, verificou-se que não somente traços culturais diferentes, mas também preconceitos constituíram barreiras nas relações de trabalho. Esse aspecto foi constatado nos casos de brasileiros expatriados, independentemente da atividade, como pode ser observado no depoimento do brasileiro que assumiu um posto gerencial na Alemanha:

“..a gente, chegando um pouco mais alto na pirâmide da empresa, a concorrência é muito grande. Então, chegando uma pessoa de fora, esta não é recebida da maneira mais calorosa. Eles nos testam, procuram criar armadilhas para provar que somos incompetentes, que somos estrangeiros de terceiro mundo e não sabemos nada... Acima de mim na agência só havia uma pessoa e era alemã. No início ela fez de tudo para mandar-me de volta, ela não queria que eu ficasse. Até mesmo, ela chegou a procurar uns aposentados lá, outros gerentes de bancos que tivessem experiência de Brasil, que falassem português, mas tudo foi feito com muita cortesia, com muita educação, no subterrâneo. “

Se, por um lado, o preconceito estigmatiza o indivíduo, constatou-se, por outro, que há elementos compartilhados, como é o caso da ética. Assim, um dos aspectos mencionados por um dos casos que foi abrir empresa em outro país é que, “apesar das diferenças culturais, a ética é igual”:

“...o grupo de pessoas que tem contato com o comércio da seda tem o hábito alimentar diferente, a religião diferente; mas a ética é a mesma, o que é certo é certo: é certo em japonês, inglês, francês, alemão.”

É importante salientar que há um esforço por parte do indivíduo para integrarse às normas da organização ou do trabalho. Em algumas situações, o expatriado conforma-se com normas de trabalho diferentes daquelas do país de origem, tal como no seguinte caso:

"Os alemães têm o seguinte principio: quem é chefe tem de chegar antes, trabalhar mais e sair depois. Você não tem de demonstrar sua capacidade pela sua autoridade; mas tem de demonstrar pela sua competência..” 
Entretanto, se o grau de autonomia for razoável, o expatriado procura introduzir seu costume na organização, tal como:

“Já tenho um grupo de fornecedores que sabe como nós trabalhamos. No começo a gente não tinha prazos cumpridos e eu perguntava: mas por que você não me entregou a mercadoria? a resposta era: ah! eu tive problemas, não deu para mandar. Mas eu não tenho culpa dos problemas dele. O problema é que eu assumo compromissos e conto com ele para esses compromissos. Se ele não cumpre, quebra uma corrente. Hoje eu já tenho fornecedores que se encaixam no nosso padrão; mas, mesmo assim, eu preciso estar olhando isso".

Outro aspecto interessante, apontado por um dos expatriados que trabalha no Brasil, consistiu na comparação entre as relações de trabalho daqui e de seu país:

"Aqui no Brasil as pessoas mantêm amizades dentro e fora da empresa, são amigas no trabalho e fora do trabalho. Lá, as relações de trabalho são só de trabalho. Dificilmente você tem amigos do trabalho fora do trabalho. São grupos separados que não se misturam. Inclusive estava aqui na semana passada o financeiro francês e saímos para dar uma volta com o pessoal da fábrica e ele achou impressionante a relação que tem fora e dentro da empresa. Ele é um financeiro novo, fez duas ou três viagens ao Brasil e ficou impressionado com isso! Ele achou legal!...isso não existe na França, na Europa. Não se relacionam, não tem passarela entre os dois mundos”.

Outro depoimento de certo expatriado, que trabalhou no Japão, fez referência às relações de trabalho entre ele e o seu superior, apontando a diferença cultural nesse relacionamento, se comparado à sua cultura de origem:

“..o chefe que eu tinha era assim: às vezes ele precisava de você e ele ficava conversando: e aí, tudo bem? conversava assuntos de que eu gostava e descobriu que eu gostava de computador.. aí embalava o assunto; mas quando não precisava, era brabo e não ligava para mim, é bem assim”.

Ainda no tocante às relações de trabalho, há o discurso de uma brasileira expatriada para a França. Ela manifestou sua comparação entre a facilidade com que se demitem empregados das empresas brasileiras, ao passo que na França, de acordo com ela:

“..para um francês ser demitido ou ele é muito ruim de serviço, ou então a empresa quebrou. A empresa só quebra mesmo, quando não tem jeito, porque o Estado vai lá e ampara a empresa também”. 
Por outro lado, no depoimento da expatriada que abriu empresa no Paraguai, as relações de trabalho são difíceis em razão do comportamento dos nativos e da cultura local:

“.. eles não têm aquele compromisso de fazer as coisas. Se chover, ele acha que não precisa ir trabalhar; se está com dor de cabeça, não precisa ir trabalhar; se a mãe está com dor de cabeça, não precisa ir trabalhar. Eles não assumem nada, são muito omissos.”

O que se pode depreender dos discursos relativos às situações de trabalho é que cada situação vivida resultou em diferentes percepções. Desta forma, é possível que variáveis como o nível hierárquico ocupado, o nível econômico do país de origem e do de destino, os tipos de cultura - individualista ou coletivista contribuíram para que uma ênfase maior no indivíduo ou no sistema predominasse e, deste modo, as percepções foram conflitantes em relação a esses aspectos.

A experiência intercultural desses indivíduos mostrou que a visão de si é reformulada, quando o indivíduo consegue integrar-se na nova cultura, obtendo aí cooperação e reconhecimento. Entretanto, quando o indivíduo vivencia conflitos, não reconhecimento e pouca ou nenhuma socialização com o outro, parece que a reconstrução de uma nova identidade não ocorre. Acredita-se que, nesses casos, nos quais o indivíduo não consegue integrar-se à cultura local, é possível que dissonâncias dêem lugar à nova identidade, a menos que ele retorne para a sua cultura de origem.

Para resumir as fases do processo de expatriação e a renovação da identidade, selecionou-se o seguinte depoimento que, de maneira simples, resume o processo:

"Você chega e leva um choque, depois se acostuma, aí depois não sei se você enjoa...Você fica cansado de ver aquele povo diferente, mas depois você volta para cá e sente falta de lá”.

Em suma, as narrativas dos sujeitos deste estudo constituem relatos de experiências por eles vividas, que não são necessariamente generalizadas para eventos similares, mas que demonstraram a necessidade de estudos adicionais em situações de trabalho que resultam em variações culturais e que exercem impacto em expatriados, tais como os seguintes: horários e jornadas de trabalho; relacionamentos/amizades no trabalho; comprometimento no trabalho e cumprimento de prazos e horários de compromissos. Outro aspecto importante é a necessidade de estudos com repatriados, pois se verificou que a situação de repatriação é tão ou mais complexa do que a de expatriação. 
Após a discussão dos casos estudados, procurou-se apontar possíveis implicações dos aspectos mencionados no âmbito da gestão organizacional, que são apresentadas na seqüência.

\section{Possíveis Implicações no Contexto da Gestão Organizacional}

Ao analisar casos de indivíduos expatriados em diferentes situações de trabalhos e em diferentes países, pode-se perceber que algumas dificuldades são comuns a todos os casos, principalmente porque se trata de culturas diferentes. Um dos aspectos diz respeito ao pouco conhecimento da dinâmica social da cultura na qual eles foram inserir-se. Deste modo, constatou-se que explorar aspectos culturais, principalmente ligados ao mundo dos negócios e do trabalho, pode ser útil para facilitar o intercâmbio internacional no mundo do trabalho, podendo facilitar as relações de trabalho dessa natureza.

Um segundo ponto é que os indivíduos que tiveram experiência de expatriação têm nova visão do seu ambiente, que pode ser explorada no trabalho, principalmente quando repatriados. Nesse aspecto, as organizações poderiam criar programas especiais de apadrinhamento para preparo de outros indivíduos que se expatriam ou até mesmo alocar esses indivíduos em programas que visem a introduzir mudanças nas organizações, uma vez que a experiência que tiveram os preparou para enfrentar situações que requeiram nova postura diante dos fatos.

Outra implicação, tanto do ponto de vista pessoal quanto organizacional, diz respeito a aposentadorias de expatriados. É necessário que empresas e indivíduos que se expatriam para trabalhar pensem nas formas de contribuição para o tempo de trabalho no exterior, a fim de não enfrentarem problemas futuros.

Outra questão, já ressaltada em outros estudos (Freitas, 2000), é que, em casos de repatriação, a família do indivíduo deve ser incluída nos planos de deslocamento, porque ela atua como grupo de apoio ao indivíduo, intermediário entre o social assimilado e as novas normas do país estrangeiro. Além disso, na medida do possível, o conhecimento do idioma local, se previamente adquirido, contribuirá para uma inserção mais rápida na nova cultura.

Outro indicativo deste estudo é que experiências anteriores, mesmo sem algum vínculo de trabalho, podem amenizar os impactos da expatriação. Assim, empresas que visam enviar seus funcionários para outros países podem estimular e apoiar visitas prévias e rápidas, em filiais no exterior. 
Os resultados apontados neste estudo apontam que indivíduos que passaram por experiências de repatriação podem ter grande potencial e, nesse sentido, as empresas podem levar em consideração experiências de repatriação no momento de recrutar indivíduos para seus cargos.

Finalmente, verificou-se a necessidade de algum suporte por parte das organizações para integrar indivíduos à cultura local e organizacional, o que pode ocorrer em conjunto com programas de gestão da diversidade (Fleury, 1999).

\section{Conclusão}

Este estudo possibilitou uma compreensão dos tipos de relações decorrentes de processos de expatriação, principalmente porque abrangeu situações diversas de trabalho no exterior. Apesar da diversidade de situações de trabalho, a experiência de alteridade foi bastante semelhante nos casos estudados.

Constatou-se que, na fase inicial da expatriação, a imersão dos indivíduos em outra cultura é acompanhada de exigências sociopsíquicas decorrentes da tentativa de enxergar-se na visão do outro, que constitui uma forma de verificar a aceitação social na nova cultura. Esses aspectos pareceram mais intensos do que as dificuldades da atividade em si. Há um esforço por parte do indivíduo em compreender, nas linhas e entrelinhas, os significados culturais do local onde está vivendo. Da mesma forma, quando retorna ao seu ambiente de origem, esse processo se repete; portanto expatriação e repatriação são fenômenos nos quais a alteridade tem grande impacto e que não podem ser desconsiderados em situações de trabalho.

No que diz respeito a situações de trabalho, foram constatadas diferenças que podem estar associadas a fatores culturais, como também, provavelmente, a diferentes posições hierárquicas ocupadas pelos indivíduos.

Outra constatação deste estudo é que não é em todas as situações que os expatriados conseguiram romper a barreira cultural e integrar-se à nova cultura. Nesses casos, houve baixa percepção da visão do outro.

Uma das limitações encontradas neste estudo foi o fato de ter apenas um ou dois indivíduos para cada tipo de situação de trabalho estudada. Destarte, os resultados poderiam ser mais consistentes, se houvessem grupos maiores para 
cada tipo de situação de expatriado: empresário, empregados, executivos e autônomos.

De qualquer forma, ficou evidente a necessidade de estudos que explorem aspectos culturais ligados às relações de trabalho, tanto para subsidiar análises de casos, como também para referencial de pessoas que passarão por situações de trabalho como expatriados, porquanto, ainda que o processo de mundialização implique certa unificação cultural, muitas diferenças ainda estão presentes. Nesse sentido, os casos estudados são exemplos de que a assimilação da diversidade cultural é o maior benefício do trabalho do expatriado.

\section{Artigo recebido em 01.10.2003. Aprovado em 28.01.2004.}

\section{REFERÊNCIAS}

\section{ARRUDA, Â.}

O ambiente natural e seus habitantes no imaginário Brasileiro: Negociando a diferença. In: ARRUDA, Ângela (org.), Representando a alteridade. 2. ed. Petrópolis: Vozes, 2002.

\section{BAUDRILLARD, J.;}

\section{GUILLAUME, M.}

Figures de l'altérité. Paris: Descartes \& Cie, 1994.

\section{CUCHE, D.}

La notion de culture dans les sciences sociales. Paris: Éditions La Découverte, 1996.

DESCHAMPS, J.C. et al.

Vies Sociales: L'identité sociale - la construction de l'individu dans les relations entre groupes. Grenoble: Presses Universitaires, 1999.
DUBAR, C.

La Socialisation. Construction des identités sociales et professionnnelles. Paris: Armand Colin, 1996.

DUVEEN,G

A construção da alteridade. In: ARRUDA, Ângela (org.), Representando a alteridade. 2. ed. Petrópolis, Vozes, 2002.

\section{FLEURY, M.T.}

Gerenciando a diversidade cultural experiências de empresas brasileiras. In: ENCONTROANUALDAANPAD, 23., 1999, Foz do Iguaçu. Anais... Foz do Iguaçu, 1999.

FREITAS, M. E.

Vida de executivo expatriado: a festa vestida de riso ou de choro. In: ENCONTRO ANUAL DA ANPAD, 24., 2000, Florianópolis. Anais... Florianópolis, 2000. 


\section{GUARESHI, P.}

Alteridade e relação: Uma perspectiva crítica. In: ARRUDA, Ângela (org.), Representando a alteridade. 2. ed. Petrópolis: Vozes, 2002.

\section{HOFSTEDE, G}

Culture and Organizations. Software of the Mind. New York: Mcgraw-Hill, 1997.

\section{JODELET, D.}

A alteridade como produto e processo psico-social. In: ARRUDA, Ângela (org.), Representando a alteridade. 2. ed. Petrópolis: Vozes, 2002.

\section{JOFFE, $\mathrm{H}$.}

Degradação, desejo e “o outro”. In: ARRUDA, Ângela (org.), Representando a alteridade. 2. ed. Petrópolis: Vozes, 2002.

\section{JOLY,A.}

Alteridade: Ser executivo no Exterior. In: CHANLAT, J. (coord.). O Indivíduo na organização. São Paulo: Atlas, 1996.

\section{JOVCHELOVITCH, S.}

Re(des)cobrindo o outro: Para um entendimento da alteridade na Teoria das representações sociais. In: ARRUDA, Â. (org.), Representando a alteridade. 2. ed. Petrópolis: Vozes, 2002.

KETS de VRIES, M. F. R.

Liderança na empresa: como o comportamento dos líderes afeta a cultura interna. São Paulo, Atlas, 1997.

\section{KIRK, J.;}

MILLER, M.L.

Reliability and Validity in qualitative research. London: Sage, 1986.

\section{RIBEIRO, J.U.}

Um brasileiro em Berlim. Rio de Janeiro: Nova Fronteira, 1995.

\section{RICOEUR, P.}

O si-mesmo como um outro. São Paulo: Papirus, 1990.

\section{YIN, R.K.}

Case Study Research. Design and Methods. London: Sage, 1988. 